\title{
A nude mouse model of obesity to study the mechanisms of resistance to aromatase inhibitors
}

\author{
Amanda Schech ${ }^{1}$, Stephen Yu ${ }^{1}$, Olga Goloubeva ${ }^{2}$, John McLenithan ${ }^{3}$ and Gauri Sabnis \\ ${ }^{1}$ Department of Pharmacology, and ${ }^{2}$ Division of Biostatistics, University of Maryland School of Medicine, \\ University of Maryland Marlene and Stewart Greenebaum Cancer Center, Baltimore, Maryland, USA \\ ${ }^{3}$ Department of Medicine and Physiology, University of Maryland School of Medicine, Baltimore, Maryland, USA
}

\author{
Correspondence \\ should be addressed \\ to G Sabnis \\ Email \\ gsabnis@som.umaryland.edu
}

\begin{abstract}
Obesity is a risk factor for breast cancer progression. Breast cancer patients who are overweight or obese or have excess abdominal fat have an increased risk of local or distant recurrence and cancer-related death. Hormone depletion therapies can also cause weight gain, exacerbating the risk for these patients. To understand the effect of obesity on hormone-dependent human breast cancer tumors, we fed ovariectomized athymic nude mice a diet containing $45 \% \mathrm{kcal}$ fat and $17 \% \mathrm{kcal}$ sucrose (high fat sucrose diet (HFSD)), $10 \% \mathrm{kcal}$ fat (low fat diet (LFD)), or a standard chow diet (chow). The mice fed the HFSD developed metabolic abnormalities consistent with the development of obesity such as weight gain, high fasting blood glucose, and impaired glucose tolerance. These mice also developed hyperinsulinemia and insulin resistance. The obese mice also had a higher tumor growth rate compared to the lean mice. Furthermore, the obese mice showed a significantly reduced responsiveness to letrozole. To understand the role of obesity in this reduced responsiveness, we examined the effect of insulin on the growth of MCF-7Ca cells in response to estrogen or letrozole. The presence of insulin rendered MCF-7Ca cells less responsive to estrogen and letrozole. Exogenous insulin treatment of MCF-7Ca cells also resulted in increased p-Akt as well as ligand-independent phosphorylation of ER $\alpha$. These findings suggest that diet-induced obesity may result in reduced responsiveness of tumors to letrozole due to the development of hyperinsulinemia. We conclude that obesity influences the response and resistance of breast cancer tumors to aromatase inhibitor treatment.
\end{abstract}
Key Words
- aromatase inhibitors
- diet-induced-obesity
- MCF-7Ca xenografts
- breast cancer

\section{Introduction}

Obesity ( $\sim 30 \%$ Americans) and breast cancer (one in eight lifetime risk) together affect a significant proportion of the female population. Therefore, the role of obesity in breast cancer is an important question. Obesity is characterized by not only increased adipose burden but also changes in metabolism and adipose biology. Elevated serum insulin levels (hyperinsulinemia), insulin resistance, and the interaction with cancer-associated adipocytes can provide cancer cells with a survival benefit not observed in a leaner body. Obesity leads to altered expression of hormones, growth factors, and inflammatory markers, such as cytokines and adipokines. These together promote cancer cell survival, angiogenesis, and metastasis and reduce apoptosis. Breast adipose tissue of obese breast cancer

Published by Bioscientifica Ltd 
patients shows distinct crown-like structures (CLS), which are macrophage infiltrates (Morris et al. 2011). These macrophages produce a variety of pro-inflammatory factors that can promote tumor growth and invasion. Studies have suggested that obesity and the resulting chronic inflammatory state increase aromatase expression and estrogen synthesis, which can result in tumor growth (Morris et al. 2011, Subbaramaiah et al. 2011). These findings may also explain why the aromatase inhibitor (AI) anastrozole was less effective in obese women as compared to women of normal weight (Sestak et al. 2010). Moreover, breast cancer patients treated with hormone depletion therapy such as AIs gain weight during treatment (Redig \& Munshi 2010, Champ et al. 2012). In a mouse model, high doses of letrozole have been shown to induce the enlargement of adipocytes and insulin insensitivity (Maliqueo et al. 2013). Supporting these findings, studies in the aromatase knockout (ArKO) mouse show that by 1 year of age mice have significantly higher levels of insulin as well as leptin, along with two to four times more visceral adiposity; the increase in adiposity was not accompanied by weight gain, but rather by loss of lean body mass, i.e., skeletal muscle mass (Jones et al. 2000, Simpson et al. 2005). Furthermore, humans with aromatase deficiency also have marked increases in glucose and insulin levels (Maffei et al. 2004, Simpson et al. 2005).

Despite all of these known phenotypic differences in obese patients, cancer treatment regimens do not take into account the modulatory effects of obesity on tumor growth and drug responsiveness. We postulate that breast cancers in obese patients are phenotypically different from those of leaner patients and, as such, employ different mechanisms of resistance to treatment, resulting in relapse and progression. An understanding of the differences in the adaptive mechanisms that cancer cells utilize under the influence of obesity is an important step in better tailoring secondary therapies to treat recurrent breast cancers.

About $75 \%$ of the patients diagnosed with breast cancer are hormone sensitive and responsive to tamoxifen and AIs. Although AIs have significantly improved the outcome of hormone-sensitive postmenopausal breast cancer, not all patients respond to AI despite the presence of estrogen receptors in their tumors, and those that do respond eventually become resistant. Therefore, understanding the mechanisms of resistance to AIs is crucial for advances in treatment. Several mechanisms and pathways have been implicated in the development of resistance to AIs, and newer pathway inhibitors are being developed to overcome resistance (Johnston 2005, 2006). However, it is unknown which pathway is activated in a particular subset of patients, and clinical trials have also emphasized the importance of patient selection (Johnston et al. 2008). Heterogeneity in response and resistance to AIs is not completely understood and we hypothesize that the presence of obesity (and its underlying molecular phenotype) is one of the responsible factors. Because breast cancer is exposed to a dramatically different hormonal milieu on the development of obesity, understanding the influence of obesity on the resistance to AIs and response to secondary therapies is important. In the current study, we have developed and characterized a mouse model of obesity to study the influence of obesity on the growth of human tumors and their response to treatment with the AI letrozole.

\section{Materials and methods}

\section{Materials}

DMEM, penicillin/streptomycin solution (10 $000 \mathrm{IU}$ each), $0.25 \%$ trypsin-1 mM EDTA solution, Dulbecco's PBS (DPBS), and G418 were obtained from Life Technologies. Human insulin and Matrigel were obtained from Sigma Chemical Company. Antibodies against phospho$\mathrm{ER} \alpha$ (S118 and S167) were purchased from Millipore (Billerica, MA, USA). Antibodies against p-Akt and Akt were purchased from Cell Signaling Technology (Beverly, MA, USA). The antibody against ER $\alpha$ was purchased from Santa Cruz Biotechnology. Androstenedione $\left(\Delta^{4} \mathrm{~A}\right)$ was purchased from Steraloids (Newport, RI, USA).

MCF-7 human breast cancer cells that are stably transfected with the human placental aromatase gene (MCF-7Ca) were kindly provided by Dr S Chen (City of Hope, Duarte, CA, USA) (Zhou et al. 1990). Letrozole was kindly provided by Novartis Pharma.

\section{Cell culture}

MCF-7Ca cells were routinely cultured in DMEM supplemented with $5 \%$ fetal bovine serum (FBS), $1 \%$ penicillin/ streptomycin, and $700 \mu \mathrm{g} / \mathrm{ml} \mathrm{G}_{418}$ (Zhou et al. 1990, Sabnis et al. 2005). Cell proliferation assays were performed using the MTT (3-(4,5-dimethylthiazol-2-yl)-2,5diphenyltetrazolium) assay as described earlier (Sabnis et al. 2005). The results were expressed as a percentage of the vehicle-treated control.

\section{Cell line authentication}

The cell line used in this study was authenticated using CellCheck service (microsatellite marker short tandem

Published by Bioscientifica Ltd. 
repeat (STR) analysis) provided by Idexx Radil (Columbia, MO, USA). The cell lines were found to be identical to the genetic profile reported for the MCF-7 cell line (ATCC\# HTB-22). The authenticated cells were inoculated in mice at passage 10 and used for in vitro studies at passage number $<20$.

\section{Nude mouse model of diet-induced obesity}

All animal studies were performed according to the guidelines and approval of the Animal Care and Use Committee of the University of Maryland, Baltimore. Female ovariectomized (OVX) athymic nude mice 4-6 weeks of age were obtained from the National Cancer Institute - Frederick Cancer Research and Development Center (Frederick, MD, USA). The mice were housed in a pathogen-free environment under controlled conditions of light and humidity in a temperature-controlled $\left(22^{\circ} \mathrm{C}\right)$ facility with a strict $12 \mathrm{~h}$ light: $12 \mathrm{~h}$ darkness cycle and received food and water ad libitum. These mice were fed a $45 \%$ kcal fat (Research Diets, New Brunswick, NJ, USA) diet containing primarily lard with $17 \%$ sucrose to produce diet-induced obesity (DIO) (high fat sucrose diet (HFSD)) or a $10 \%$ low fat control with $0 \%$ sucrose (low fat diet (LFD)) diet for an indicated time. A standard chow-based diet was used as a comparison to previous results ( $n=10 /$ group).

\section{Fasting glucose and insulin levels}

On week 6 after initiating diets, fasting glucose and i.p. glucose tolerance test (IP-GTT) measurements were performed. To measure fasting plasma glucose levels, mice were fasted for $6 \mathrm{~h}$ during the day (Andrikopoulos et al. 2008). Food was removed from the cages but mice were allowed free access to water. Mice were weighed and baseline blood glucose levels were determined using a glucometer (TRUEResult Blood Glucose Kit, Nipro Diagnostics, Fort Lauderdel, FL, USA) and glucose test strips according to the manufacturer's instructions. Blood was acquired by a tailvein prick using a lancet. For insulin measurements, blood was collected using retro-orbital bleeding in anesthetized mice $(n=10)$. Serum C-peptide levels were measured using rat/mouse C-peptide ELISA (Millipore).

\section{Glucose and insulin tolerance tests}

Mice were weighed and fasted for $6 \mathrm{~h}(n=10)$ and then injected intraperitoneally (i.p.) with $2 \mathrm{~g} / \mathrm{kg}$ of glucose (for IP-GTT). Glucose quantification was performed with the glucometer before injection (time 0 ) and at 5, 10, 15, 30,
60,90 , and $120 \mathrm{~min}$ after injection. For insulin measurement, blood was collected (at $0,15,30$, and 90 min) using retro-orbital eye bleeding and then quantified with serum C-peptide ELISA. Mice were given fluid replacement at the end of the blood collection period. For the i.p. insulin tolerance test (IP-ITT), regular recombinant human insulin (Sigma) was injected at $0.5 \mathrm{IU} / \mathrm{kg}$ and blood glucose was measured using the glucometer before injection (time 0 ) and at $5,10,15,30,60,90$, and $120 \mathrm{~min}$ after the injection.

\section{Tumor growth in OVX female athymic nude mice}

The mice were fed the diets described above for 6 weeks and the body weight of each mouse was measured every week. On week 6, the mice were inoculated with MCF-7Ca cells. The tumor xenografts of MCF-7Ca cells were grown in the mice as previously described (Yue et al. 1994, Sabnis et al. 2008, 2009, 2010, 2013a,b). Briefly, each mouse received s.c. inoculations in one site per flank with $100 \mu \mathrm{l}$ of cell suspension containing $\sim 2.5 \times 10^{6}$ cells in Matrigel. The mice were injected daily with supplemental $\Delta^{4} \mathrm{~A}$ $(100 \mu \mathrm{g} /$ day $)$. Weekly tumor measurements began 3 weeks after cell inoculations and treatments began when the tumors reached $\sim 250 \mathrm{~mm}^{3}$. Tumors were measured with calipers and volumes were calculated using the formula $4 / 3 \pi r_{1}^{2} r_{2}\left(r_{1}<r_{2}\right)$. Mice were assigned to groups for treatment so that there was no statistically significant difference in tumor volume among the groups at the beginning of treatment $(n=5)$. Letrozole and $\Delta^{4} \mathrm{~A}$ for injection were prepared using $0.3 \%$ weight per volume (w/v) hydroxypropyl cellulose (HPC) in $0.9 \% \mathrm{w} / \mathrm{v}$ $\mathrm{NaCl}$ solution and injected s.c. five times weekly. The doses of letrozole $(10 \mu \mathrm{g} / \mathrm{day})$ and $\Delta^{4} \mathrm{~A}(100 \mu \mathrm{g} /$ day $)$ used are as previously determined and reported (Sabnis et al. 2008, 2010).

\section{Tissue collection}

At necropsy, mice were fasted for $6 \mathrm{~h}$ and blood was collected by cardiac puncture. Tumors and adipose tissue were collected, flash frozen, and stored at $-80^{\circ} \mathrm{C}$. Adipose tissue was collected from ovarian, perirenal, mesenteric, subcutaneous/mammary, and brown fat pads. Uterine wet weight was also measured.

\section{Radiometric ${ }^{3} \mathrm{H}_{2} \mathrm{O}$ release assay for aromatase activity measurement}

For measuring aromatase activity, the tissues were homogenized in ice-cold DPBS containing protease and

Published by Bioscientifica Ltd. 
phosphatase inhibitors. The resulting homogenate was used for the aromatase activity assay. The radiometric ${ }^{3} \mathrm{H}_{2} \mathrm{O}$ release assay was performed as described previously (Long et al. 1998, Sabnis et al. 2008, 2009). The tissue homogenate was incubated for $30 \mathrm{~min}$ with $1 \mu \mathrm{Ci} / \mathrm{ml}$ of $\left[1 \beta^{3} \mathrm{H}\right] \Delta^{4} \mathrm{~A}$ as substrate in the presence of molecular oxygen and an NADPH generating system. The activity of the enzyme was calculated from the ${ }^{3} \mathrm{H}_{2} \mathrm{O}$ released during the incubation and corrected for protein concentration in the tissue homogenates.

\section{RNA extraction and RT and PCR}

RNA was extracted and purified using the RNeasy Lipid Tissue Mini Kit (Qiagen) as per manufacturer's protocol. Total RNA concentration and purity were determined using Qubit 2.0 Fluorometer (Life Technologies) using the manufacturer's protocol. RNA was diluted with DNase/ RNase free water to $0.08 \mu \mathrm{g} / \mu \mathrm{l}$, and $0.64 \mu \mathrm{g}$ of RNA was reverse transcribed with iScript cDNA Synthesis Kit (BioRad) per the manufacturer's protocol. Analysis of mRNA expression was carried out by real-time qRT-PCR as described earlier with GAPDH serving as housekeeping control (Sabnis et al. 2009). Each assay was performed three times in duplicates and the results were plotted as fold changes compared to levels in lean mice. Results were normalized to GAPDH internal control. The following murine primers were used for RT-PCR: Aromatase Forward: 5'-AAG CTC TGA CGG GCC CTG GT-3', Reverse: 5'-ACG TAG CCC GAG GTG TCG GT-3'; Cox-2 Forward: $5^{\prime}$-ATT CTT TGC CCA GCA CTT CA-3', Reverse: 5'-GGG ATA CAC CTC TCC ACC AA-3' (Subbaramaiah et al. 2012).

\section{Western blotting}

Cellular protein extracts were prepared as described earlier (Sabnis et al. 2009). A total of $25 \mu \mathrm{g}$ protein from each sample was analyzed by western blotting using SDS-PAGE as described previously (Sabnis et al. 2009). Bands were quantitated by densitometry using ImageJ. The densitometric values are corrected for $\beta$-actin loading control.

\section{Statistical analysis}

One-Way ANOVA with the Tukey Kramer post-test or Student's $t$-test was used for in vitro studies. For in vivo studies, mixed-effects models were used. The tumor volumes were analyzed with S-PLUS (7.0, Insightful Corp., Tibco, Palo Alto, CA, USA) to estimate and compare an exponential parameter ( $\beta i)$ controlling the growth rate for each treatment group.
The original values for tumor volumes were log transformed. The graphs are represented as mean \pm s.E.M. All $P$ values $<0.05$ were considered statistically significant.

\section{Results}

\section{Obesogenic diet induces obesity and glucose tolerance in athymic nude mice}

To study the effect of obesity on tumor growth and treatment resistance, we developed and characterized a mouse model of DIO. Other studies have used high fat diets to induce obesity in C57B/6J mice (Bell et al. 2008, Subbaramaiah et al. 2011). In our study, we used immune suppressed athymic nude mice to study obesity and its effects on human mammary tumors. Mice were fed an obesogenic HFSD, with $45 \%$ of the calories from saturated fat (lard) and $17 \%$ of the calories from sucrose. As a control diet, mice were fed a LFD that had $10 \% \mathrm{kcal}$ fat. We also included a group of mice fed a chow diet to compare the results with our previously published work. As shown in Fig. 1A, mice fed an HFSD gained a significant amount of weight compared to mice fed the LFD $(P=0.0036)$ or chow $\operatorname{diet}(P=0.0003)$ by week 12 (Supplementary Figure 1 , see section on supplementary data given at the end of this article). There was no statistically significant difference in weight between the mice fed the low fat and chow diets $(P=0.907)$. The rate of weight gain was also significantly higher in mice fed the HFSD compared to mice fed low fat $(P=0.0055)$ or chow $(P=0.0026)$ diets. The rate of weight gain was calculated from a linear regression line. Food intake of mice on both LFD and HFSD was not significantly $(P=0.78)$ different (data not shown). However, obesity is not merely weight gain. The underlying metabolic phenotype includes changes in levels of several hormones, growth factors, and pro-inflammatory cytokines as well as changes in the fat distribution. To study the underlying phenotype of DIO, we first examined fasting blood glucose levels and glucose tolerance with IP-GTT. The mice were fasted for $6 \mathrm{~h}$ and then blood glucose was measured at time 0 and $5,10,15,30,60,90$, and $120 \mathrm{~min}$ after injecting $2 \mathrm{~g} / \mathrm{kg}$ of D-glucose i.p. The fasting blood glucose level of mice fed the obesogenic diet was significantly higher than the mice fed the lean $(P=0.0003)$ or chow diet $(P<0.0001)$ (Fig. $1 B)$. Furthermore, the IP-GTT showed that mice fed the HFSD had significantly $(P<0.0001)$ impaired glucose tolerance compared to the mice on LF or chow diets (Fig. 1C and D). The blood glucose levels of mice fed the obesogenic diet rose to a higher level in response to i.p. D-glucose and

Published by Bioscientifica Ltd. 

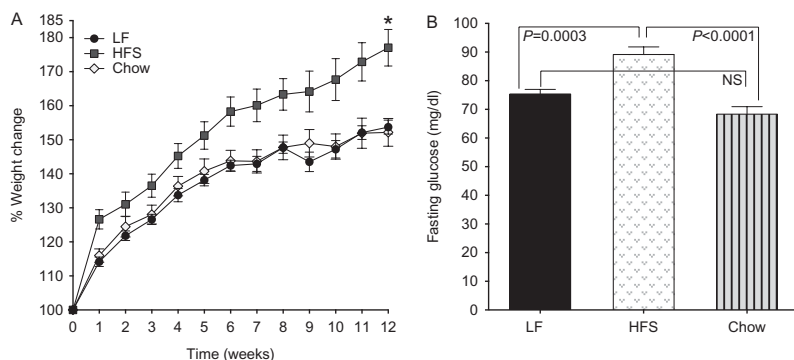

\section{Figure 1}

Effect of obesogenic diet on (A) weight gain (B) fasting blood glucose, and (C) glucose tolerance. Ovariectomized athymic nude mice were fed a diet containing $45 \%$ fat (primarily lard) and $17 \%$ sucrose (HFS) to induce obesity. A diet with $10 \%$ fat was used as a lean control diet (LF) and chow diet was used as a comparison. (A) Mice were weighed weekly and the percent change in weight was recorded. The mice fed the HFS diet gained a significant amount of weight compared to the mice fed the LF diet $(P=0.0036)$ or chow diet $(P=0.0003)$ by week 12 . (B) Mice were fasted

remained higher throughout the course of the experiment compared to the lean groups. As such, the area under the curve $_{\text {glucose }}\left(\mathrm{AUC}_{\text {glucose}}\right)$ for obese mice was significantly higher than that of the lean mice. We next evaluated the effect of OVX on glucose tolerance. Mice fed the HFSD (Fig. 2A and B) or LFD (Fig. 2C and D) had worse glucose tolerance if they were OVX, suggesting that OVX may exacerbate the effect of DIO on glucose tolerance. This effect was more pronounced in mice fed the obesogenic diet, suggesting obesity and OVX may act synergistically in a positive feedback manner to reduce glucose tolerance.

\section{Obesogenic diet induces hyperinsulinemia and insulin resistance}

As the mice exhibited impaired glucose tolerance, we measured the levels of insulin C-peptide and
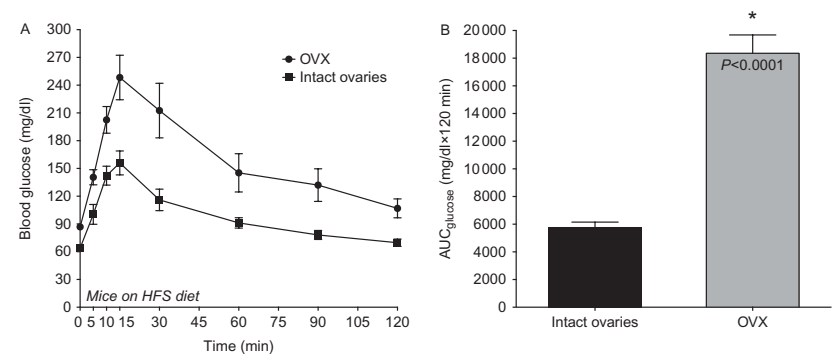

Figure 2

Effect of ovariectomy on glucose tolerance in mice fed the (A and B) obesogenic or (C and D) lean diet. Athymic nude mice with or without ovaries (OVX or intact ovaries) were fed HFS or LF diet for 6 weeks. Mice were fasted for $6 \mathrm{~h}$ during the day and then blood glucose was measured at time 0 and $5,10,15,30,60,90$, and $120 \mathrm{~min}$ after injecting $2 \mathrm{~g} / \mathrm{kg}$ of
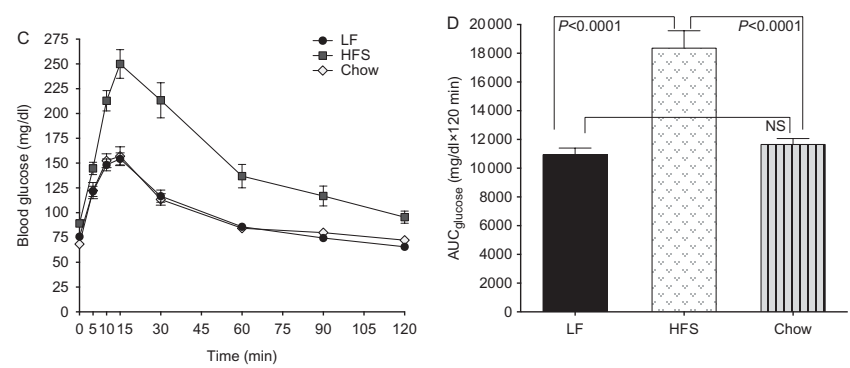

for $6 \mathrm{~h}$ during the day and fasting blood glucose was measured using a glucometer. The fasting blood glucose level of the mice fed the HFS diet was significantly higher than the mice fed the $\operatorname{LF}(P=0.0003)$ or chow diet $(P<0.0001)$. (C) For the glucose tolerance test, blood glucose was measured at time 0 and $5,10,15,30,60,90$, and $120 \mathrm{~min}$ after injecting $2 \mathrm{~g} / \mathrm{kg}$ of $\mathrm{D}$-glucose intraperitoneally in fasting mice. (D) The area under the curve (AUC) was calculated and plotted. Mice fed the HFS diet have a significantly $(P<0.001)$ higher $A_{U C}$ glucose than the mice fed the LF or chow diet.

responsiveness of the tissues to insulin. Mice were fasted for $6 \mathrm{~h}$ after which blood was collected via retro-orbital bleeding. Serum insulin levels were measured using rat/mouse C-peptide ELISA. Mice fed the obesogenic diet had significantly higher fasting insulin levels compared to mice fed the low fat $(P=0.0006)$ or chow $(P<0.0001)$ diets (Fig. 3A). The mice were also subjected to IP-GTT, and collected serum was subjected to C-peptide ELISA (Fig. 3B and C). The HFSD obese mice showed higher AUC $\mathrm{C}_{\text {-peptide }}$ compared to the mice on low fat $(P=0.0002)$ or chow $(P=0.0001)$ diets. However, the rate of increase in the insulin levels was less than in obese mice $(\sim 100 \%$ increase in lean or chow fed mice vs $12.5 \%$ increase in obese mice). This suggests reduced insulin secretion on glucose stimulus in obese mice. Next, we examined the effect of insulin on the tissue responsiveness, using IP-ITT (Fig. 3D). Recombinant human insulin was given i.p. $(0.5 \mathrm{U} / \mathrm{kg})$ and
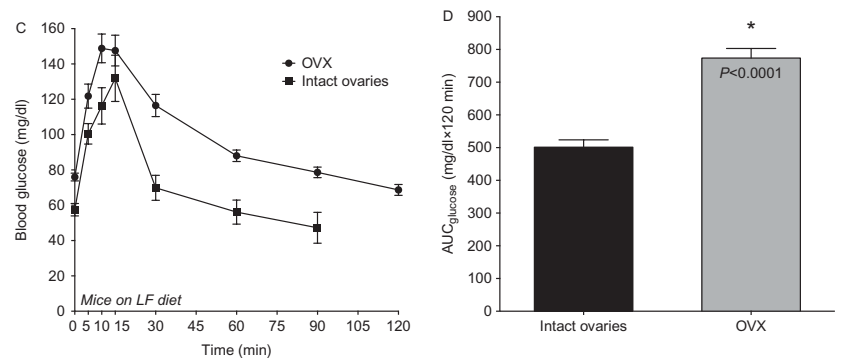

D-glucose intraperitoneally. ( $B$ and D) The area under the curve (AUC) was calculated and plotted. The OVX mice fed the HFS or LF diets have significantly $(* P<0.001)$ higher $A \cup C_{\text {glucose }}$ than the mice with intact ovaries fed the obesogenic or lean diets.

Published by Bioscientifica Ltd 


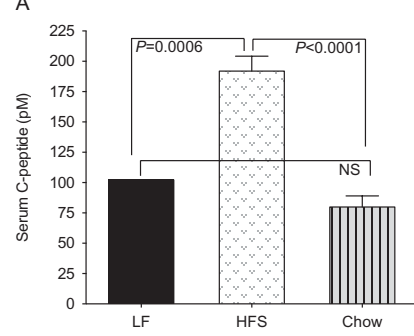

B

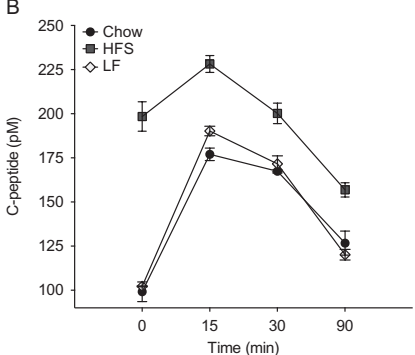

C

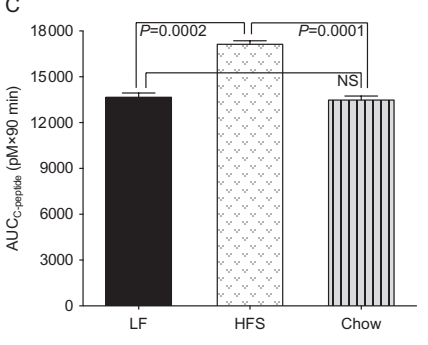

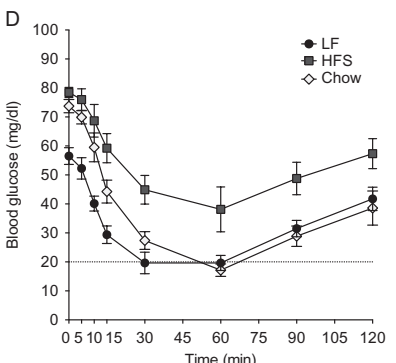

Figure 3

Effect of obesogenic diet on (A) serum insulin level and (B and $C$ ) insulin response to glucose in OVX athymic nude mice. Fasting insulin measurements were performed after 8 weeks on the diets. Mice were fasted for $6 \mathrm{~h}$ during daytime and blood was collected by retro-orbital collection method. Serum C-peptide levels were measured by ELISA. (A) Mice fed the HFSD had significantly higher fasting serum C-peptide levels than mice fed the LF $(P=0.0006)$ or the chow $(P<0.0001)$ diets. The serum C-peptide was not significantly different between the mice fed the lean or chow diet $(P=0.4211)$. (B) Blood was collected in fasting mice at time 0 and 15,30 , and $90 \mathrm{~min}$ after injecting $2 \mathrm{~g} / \mathrm{kg}$ of D-glucose intraperitoneally. Serum
C-peptide levels were measured by ELISA. (C) The area under the curve (AUC) was calculated and plotted. Mice fed the HFSD had significantly higher $\mathrm{AUC}_{\mathrm{C} \text {-peptide }}$ levels than mice fed the $\mathrm{LF}(P=0.0002)$ or the chow $(P=0.0001)$ diets. AUC $\mathrm{C}_{\mathrm{C} \text {-peptide }}$ was not significantly different between the mice fed the LF or chow diet $(P=0.875)$. (D) Effect of obesogenic diet on glucose response to insulin in OVX athymic nude mice. OVX athymic nude mice with or without ovaries (OVX or intact ovaries) were fed an obesogenic HFSD for 8 weeks. Mice were fasted for $6 \mathrm{~h}$ during the day and then blood glucose was measured at time 0 and 5, 10, 15, 30, 60, 90, and $120 \mathrm{~min}$ after injecting $0.5 \mathrm{IU} / \mathrm{kg}$ of human insulin intraperitoneally. blood glucose levels were measured using a glucometer. The mice fed low fat and chow diets had a more pronounced response to exogenous insulin than the mice fed the obesogenic diet, suggesting that the tissues of obese mice are less responsive to insulin.

\section{Insulin mediates letrozole resistance in vitro}

Obese mice exhibit significant hyperinsulinemia. Insulin can activate growth factor receptor pathways, which have been shown to be responsible for the acquisition of resistance to AIs. Hence, we evaluated the effect of insulin on the growth of MCF-7Ca cells in vitro. MCF-7Ca cells were plated in 24-well plates and serum starved for $40 \mathrm{~h}$ ( $0.1 \%$ charcoal treated serum). The cells were then treated with estradiol $\left(\mathrm{E}_{2}\right)$ or letrozole $\left(10^{-12} \mathrm{M}\right.$ to $\left.10^{-6} \mathrm{M}\right)$ for 6 days in the presence or absence of insulin $(2 \mu \mathrm{M})$ in otherwise serum-starved conditions. Cells were supplemented with $\Delta^{4} \mathrm{~A}(25 \mathrm{nM})$ when being treated with letrozole. Cell viability was measured on day 7 using the MTT assay. In the absence of insulin, $\mathrm{E}_{2}$ produced a classical biphasic dose response curve with maximum stimulation observed at $1 \mathrm{nM}$. However, in the presence of $2 \mu \mathrm{M}$ insulin, this stimulation was abrogated. However, a lower concentration of $\mathrm{E}_{2}(1 \mathrm{pM})$ showed the stimulation of cell growth when treated concomitantly with insulin (Fig. 4A). This suggests that insulin can induce hypersensitivity to $E_{2}$. Furthermore, MCF-7Ca cells showed a significantly reduced antiproliferative response to letrozole in the presence of chronic insulin (Fig. 4B). This was more pronounced at lower doses of letrozole. Taken together, these results suggest that the continuous presence of high levels of insulin affects the response of breast cancer cells to estrogen and estrogen withdrawal. We previously reported activation of growth factor receptor pathways on the acquisition of letrozole resistance. Therefore, we next examined the effect of insulin on the activation of growth factor receptor pathways, which may mediate resistance to $\mathrm{E}_{2}$ and letrozole. Treatment with insulin $(2 \mu \mathrm{M})$ for $3 \mathrm{~h}$ resulted in the activation of the insulin receptor (IR) as well as the IGF1 receptor (data not shown) and p-Akt in MCF-7Ca cells (Fig. 4C). Furthermore, $\mathrm{ER} \alpha$ was also phosphorylated following insulin treatment on Serine 167, which is known to be activated by Akt. Serine 118 (MAPK target) was not phosphorylated following treatment with insulin. This suggests that insulin can activate $\mathrm{ER} \alpha$ in a ligand independent manner through Akt and may render MCF-7Ca cells resistant to estrogen withdrawal that ensues on letrozole treatment.

\section{Obesogenic HFSD induces changes in adipose tissue mass}

Mice were euthanized after 12 weeks on the diets and adipose tissue depots were isolated, weighed, and stored at $-80^{\circ} \mathrm{C}$ for further analysis. As shown in Fig. 5A, mice fed the obesogenic diet had a significantly higher fat mass in all five sites (ovarian, mesenteric, perirenal, subcutaneous/ mammary, and brown fat depots) than mice on lean or chow diets. The adipose tissue weights are normalized to total body weight. There was no significant difference in

Published by Bioscientifica Ltd 

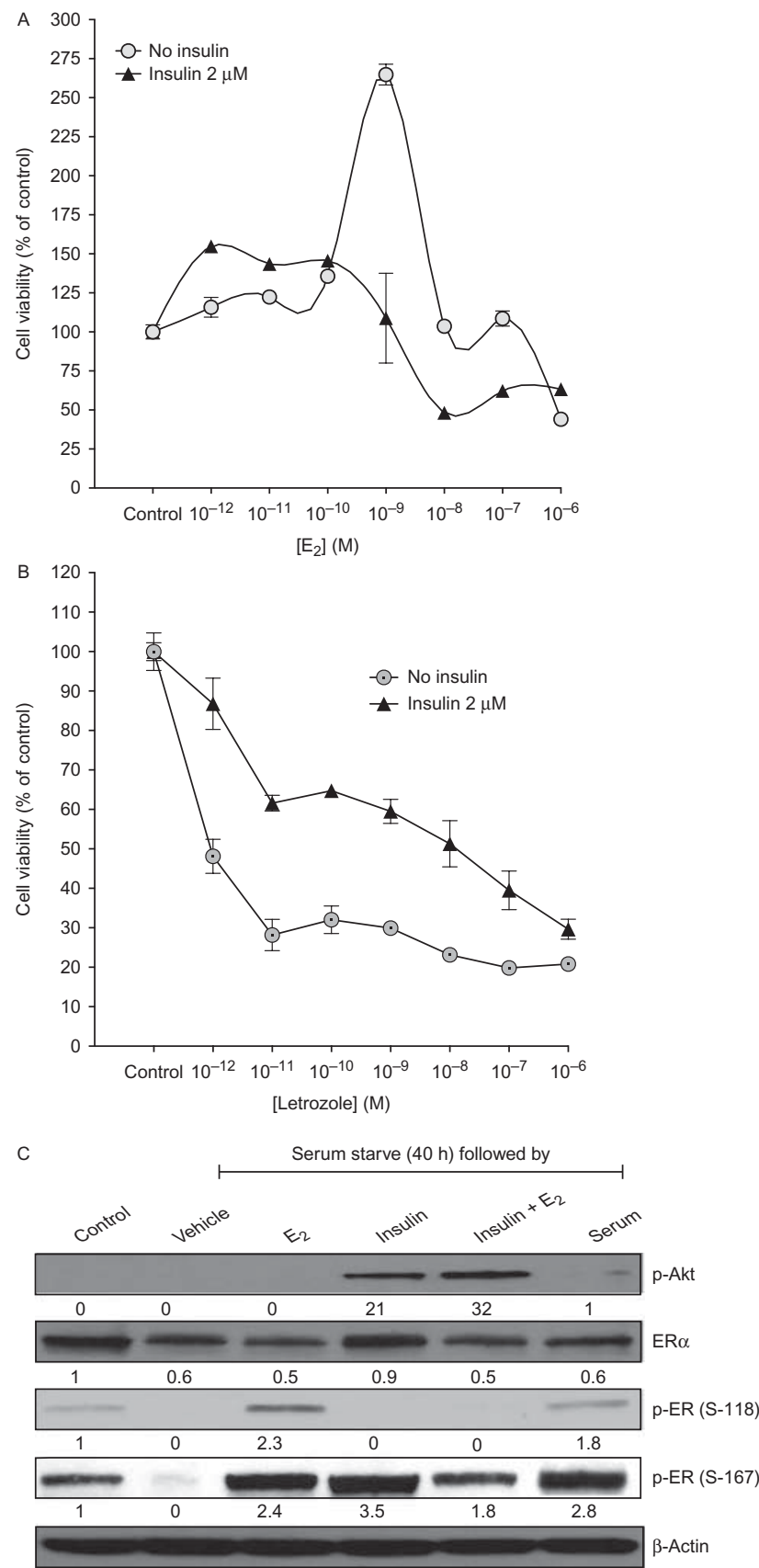

\section{Figure 4}

Effect of insulin on the growth properties of MCF-7Ca cells. Hormone dependent MCF-7Ca cells were serum starved for $40 \mathrm{~h}$ and then treated with $(A)$ estradiol $\left(E_{2}\right)$ or $(B)$ letrozole at doses $10^{-12}$ to $10^{-6} \mathrm{M}$ for 6 days in an otherwise serum-starved condition, and cell viability was measured by MTT assay. (C) Effect of insulin and $E_{2}$ on activation of growth factor pathways. MCF-7Ca cells were serum starved for $40 \mathrm{~h}$ and then treated with insulin $(2 \mu \mathrm{M}), E_{2}(1 \mathrm{nM})$, the combination of $E_{2}$ and insulin, or a serumcontaining medium for $3 h$, and the cell lysates were analyzed by western blotting. Densitometric values (corrected for $\beta$-actin loading control) show fold change compared with the control (maintained in serum-containing medium). the fat mass between mice fed the low fat vs chow diets. This suggests that weight gain induced by the obesogenic diet was due to increased adiposity. As such, this diet produced most of the comorbidities of obesity in nude mice as observed in the $\mathrm{C} 57 \mathrm{~B} / 6$ mice including weight gain and increased adiposity as well as impaired glucose tolerance, hyperinsulinemia, and insulin resistance.

\section{Obesogenic HFSD induces increased estrogen synthesis}

As the mouse uterus is extremely sensitive to estrogen stimulation, changes in uterine weight are useful in monitoring estrogenic effects in vivo (Langston \& Robinson 1935, Owens \& Ashby 2002). OVX mice not supplemented with estrogen or an estrogenic source but fed the obesogenic diet had a significantly higher uterine weight $(P=0.036)$ than mice on the LFD. This suggests that the obesogenic diet can lead to increased estrogen levels in this mouse model (Fig. 5B). Furthermore, mice that were supplemented with $\Delta^{4} \mathrm{~A}$ and fed the HFSD also had an additional increase in uterine weight, which was significantly higher than in mice receiving LF $(P=0.0013)$ or chow $(P=0.0026)$ diets. These results suggest that increased adiposity in the obese mice serves as an additional source of aromatase that can convert the administered $\Delta^{4} \mathrm{~A}$ to estrogen, which in turn can stimulate uterine growth. To corroborate our hypothesis, we examined aromatase activity (Fig. 6A) and aromatase mRNA (Fig. 6B) levels in the adipose tissue of obese and lean mice. The adipose tissue of the obese mice had significantly $(P<0.0001)$ higher levels of aromatase activity and aromatase mRNA expression than the adipose tissue of the lean mice in all adipose depots. Furthermore, visceral adipose depots such as mesenteric and perirenal had much higher levels of aromatase (mRNA and protein activity) than gonadal and subcutaneous fat depots. This suggests that visceral fat may have a greater impact than subcutaneous or gonadal fat on the production of estrogen through elevated aromatase expression. Increased production of $\mathrm{PGE}_{2}$ is observed during inflammation through increased expression of COX-2. Prostaglandin $\mathrm{PGE}_{2}$ is a known activator of the aromatase promoter (Zhao et al. 1996, Brodie et al. 2001, Karuppu et al. 2002). Therefore, we next examined the expression of COX-2 mRNA (Fig. 6C) in adipose tissues. We observed that the adipose tissue of obese mice had significantly $(P<0.0001)$ higher levels of COX-2 mRNA expression than the adipose tissue of lean mice in all adipose depots. Furthermore, visceral adipose depots such as perirenal had much higher levels of COX-2 mRNA than gonadal and subcutaneous fat depots.

Published by Bioscientifica Ltd 

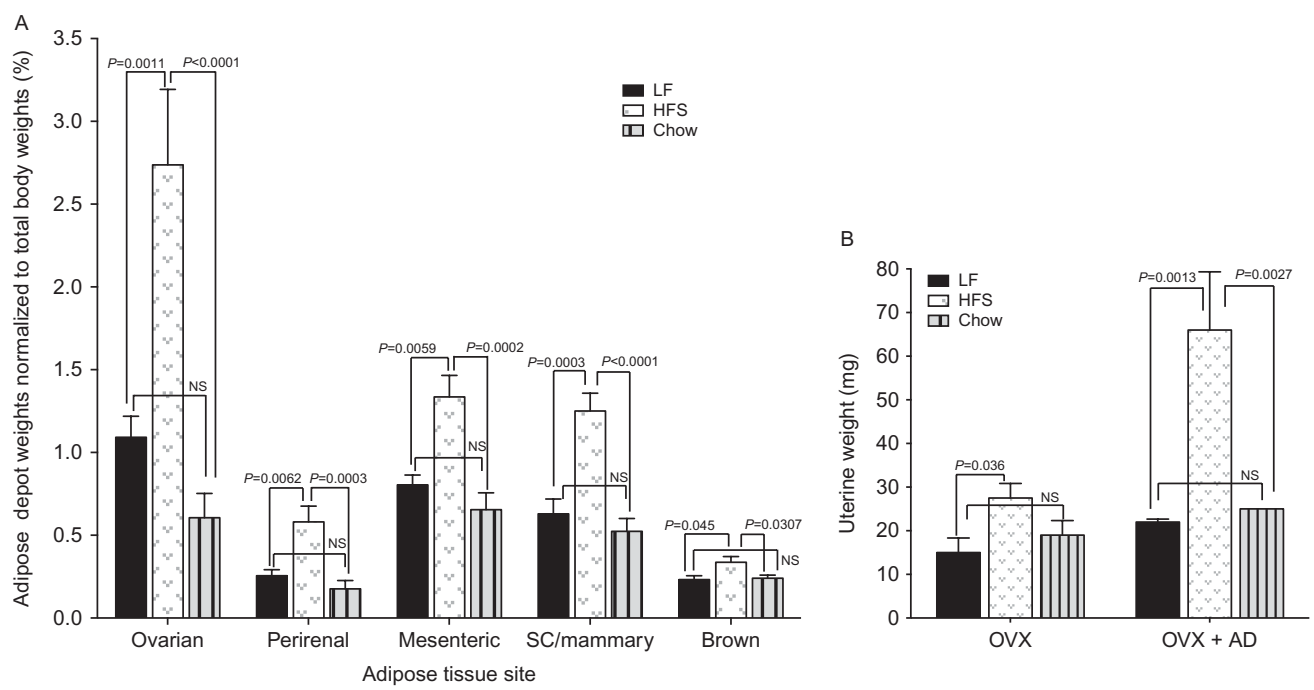

\section{Figure 5}

Changes in adipose mass in mice fed the HFS, LF, or chow diets. OVX athymic nude mice were fed HFS, LF, or chow diets for 12 weeks. Mice were fasted for $6 \mathrm{~h}$ during the day and then euthanized. Indicated adipose depots were collected, weighed, and stored at $-80^{\circ} \mathrm{C}$ for additional analysis. Mice fed the HFSD had a significantly higher fat mass than the mice fed the LF or chow diets. There was no significant difference in fat mass in the lean vs chow-fed mice. The tissue weights are normalized for total body weight and expressed as percentage. (B) Changes in uterine wet weight in mice fed the HFS, LF, or chow diets. OVX athymic nude mice were

Taken together, these results suggest that visceral adiposity may have a greater impact on breast cancer tumor growth through increased production of estrogen.

\section{Obese mice are less responsive to letrozole than lean mice}

Next, we evaluated the effect of obesity on the response of human hormone sensitive MCF-7Ca tumors to the AI letrozole. Mice were fed the obesogenic or lean diets for 6 weeks. Mice were inoculated with MCF-7Ca cells and tumors were allowed to form in the presence of the $\Delta^{4} \mathrm{~A}$ supplement. Tumor measurements started 3 weeks after inoculation of the cells and treatment with letrozole started after the tumors reached $\sim 250 \mathrm{~mm}^{3}$ (Fig. 7A). In light of the more rapid growth of the tumors in the mice fed the obesogenic diet, treatment with letrozole was started 4 weeks earlier than in the mice on either the low fat or chow diets. Mice received letrozole treatment until the tumors acquired resistance (double the initial volume). Tumor growth rates were calculated for the control group 3 weeks after inoculations and from the time treatment was started for mice in the letrozole group. As expected, the mice fed the obesogenic HFSD had significantly higher tumor growth rates $(P=0.02)$ than the lean mice (Fig. $7 \mathrm{~B})$. fed HFS, LF, or chow diets for 12 weeks. Mice were fasted for $6 \mathrm{~h}$ during the day and then euthanized. Uteri were isolated and weighed. The mice fed the HFSD had significantly higher $(P=0.036)$ uterine wet weight than the mice fed the LFD in absence of estrogenic stimulus. Additionally, in the presence of androstenedione (AD), the uterine weight was greatly increased in the mice fed the HFSD than the LF $(P=0.0013)$ or the chow $(P=0.0027)$ diets. There was no significant difference in the uterine wet weight of the mice that were fed the lean or chow diet $(P=0.959)$.

Letrozole treatment of both the obese and lean mice resulted in significant $(P=0.0436$ and 0.025 respectively) reduction in the tumor growth rate. However, lean mice receiving letrozole treatment had a significantly lower tumor growth rate than the obese mice on the letrozole treatment $(P=0.0263)$. The tumors grown in the obese mice did not regress to the same levels as tumors of the lean mice and exhibited a decreased lag period before resumption of growth. Thus, tumors growing in an obese environment exhibited diminished response to letrozole and acquired resistance (doubled in tumor volume as compared to starting volume) quicker than the tumors in the lean mice. This suggests that obesity influences the response and resistance of tumors to AIs such as letrozole.

\section{Discussion}

To study the effect of obesity on tumor response to AI treatment and resistance, we used a tumor xenograft model of DIO that mimics most aspects of human disease. Studies have shown that rodents fed a high sucrose, high fat diet have increased body weight (without any increase in food intake), abdominal fat deposition, hyperinsulinemia, and hyperglycemia and showed signs

Published by Bioscientifica Ltd 
of hepatic steatosis (Anstee \& Goldin 2006), which we also observed in our model (Supplementary Figure 2, see section on supplementary data given at the end of this article). A diet high in saturated fats and carbohydrates mimics the human diet closely and is considered the best diet for studying DIO (Panchal \& Brown 2011, Panchal et al. 2011). Obesity models that have been used previously in published obesity studies are genetically modified (such as $o b / o b$ or $d b / d b$ ) models or DIO in C $57 \mathrm{~B} / 6$ mice. However,
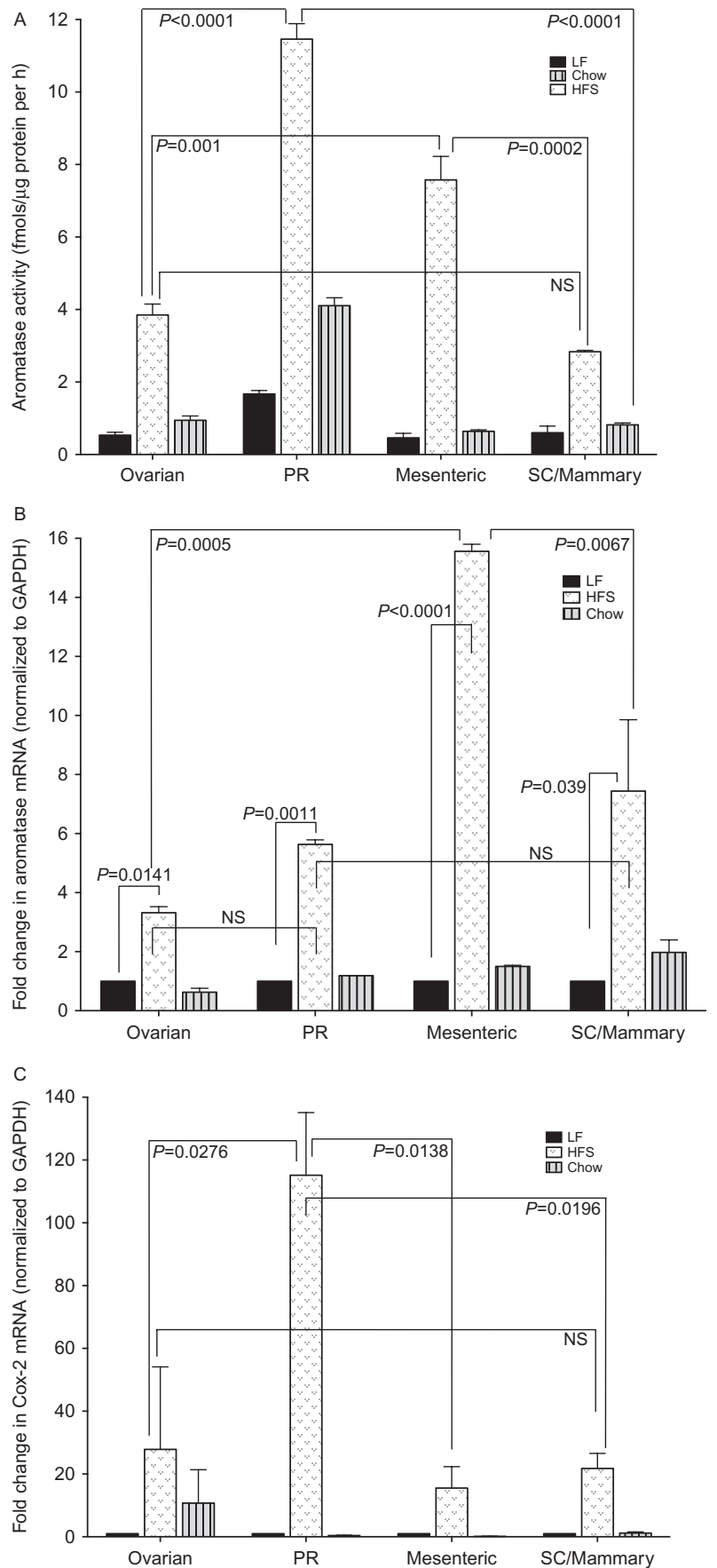

http://erc.endocrinology-journals.org DOI: 10.1530/ERC-15-0168 these models do not support the growth of human tumors, and thus, the interaction of the obesity phenotype with human tumors has not been completely understood. A few studies have used athymic nude mice for obesity studies and found that obesity induced with high caloric intake can increase the growth of MCF-7 tumors (Lamas et al. 2015) and T47D tumors (Nkhata et al. 2009). However, more studies to understand the effect of obesity on tumor response to treatment regimen are critical. In our model, lean/obese mice were inoculated with human breast cancer MCF-7Ca cells and treated with letrozole until the tumors became resistant. This new mouse model is based on our intra-tumoral aromatase xenograft model (Yue \& Brodie 1993, Yue et al. 1994, Sabnis et al. 2008, 2009). This model mimics the postmenopausal breast cancer patient, as the source of estrogen is from nonovarian tissue and is not under gonadotropin regulation. However, as the mouse has no significant production of peripherally formed estrogen, the MCF-7 human breast cancer cells stably transfected with the human aromatase gene (MCF-7Ca) (Zhou et al. 1990) serve as an autocrine source of estrogen to stimulate tumor growth in OVX, immune-suppressed mice. The resulting tumors synthesize estrogen from supplemented androstenedione $\left(\Delta^{4} \mathrm{~A}\right)$ and proliferate in response to estrogen acting via $E R \alpha$. These tumors are therefore useful for studying and comparing the effects of both antiestrogens (AEs) and AIs in the same model system (Yue et al. 1994). Clinical trials (BIG 1-98, ATAC, MA-17) have now confirmed the results of our xenograft model (Baum et al. 2002, Goss et al. 2003, 2005, Thurlimann et al. 2005, Goss 2006). As found in

\section{Figure 6}

Changes in aromatase activity in mice fed the HFS, LF, or chow diet. OVX athymic nude mice were fed HFS, LF, or chow diets for 12 weeks. Mice were fasted for $6 \mathrm{~h}$ during the day and then euthanized. Adipose depots were collected, weighed, and stored at $-80^{\circ} \mathrm{C}$ for additional analysis. Indicated adipose tissue were homogenized and subjected to aromatase activity assay as described in Materials and Methods. Each adipose depot of the mice fed the HFSD had significantly higher aromatase activity than that of the mice fed the LF or chow diets. Furthermore, visceral adipose tissues such as mesenteric and perirenal had a significantly higher activity than the peripheral depots such as ovarian or subcutaneous in the obese mice. Changes in (B) aromatase and (C) Cox-2mRNA in mice fed the HFS, LF, or chow diet. The indicated adipose tissue of mice fed the HFS, LF, or chow diets were homogenized and subjected to QRT-PCR as described in Materials and methods. Each adipose depot of the mice fed the HFSD had significantly higher aromatase and Cox-2 mRNA than that of the mice fed the LF or chow diets. Furthermore, visceral adipose tissue of the mesenteric and perirenal depot had a significantly higher expression of aromatase and Cox-2 respectively than the peripheral depots such as ovarian or subcutaneous in the obese mice.

Published by Bioscientifica Ltd. 

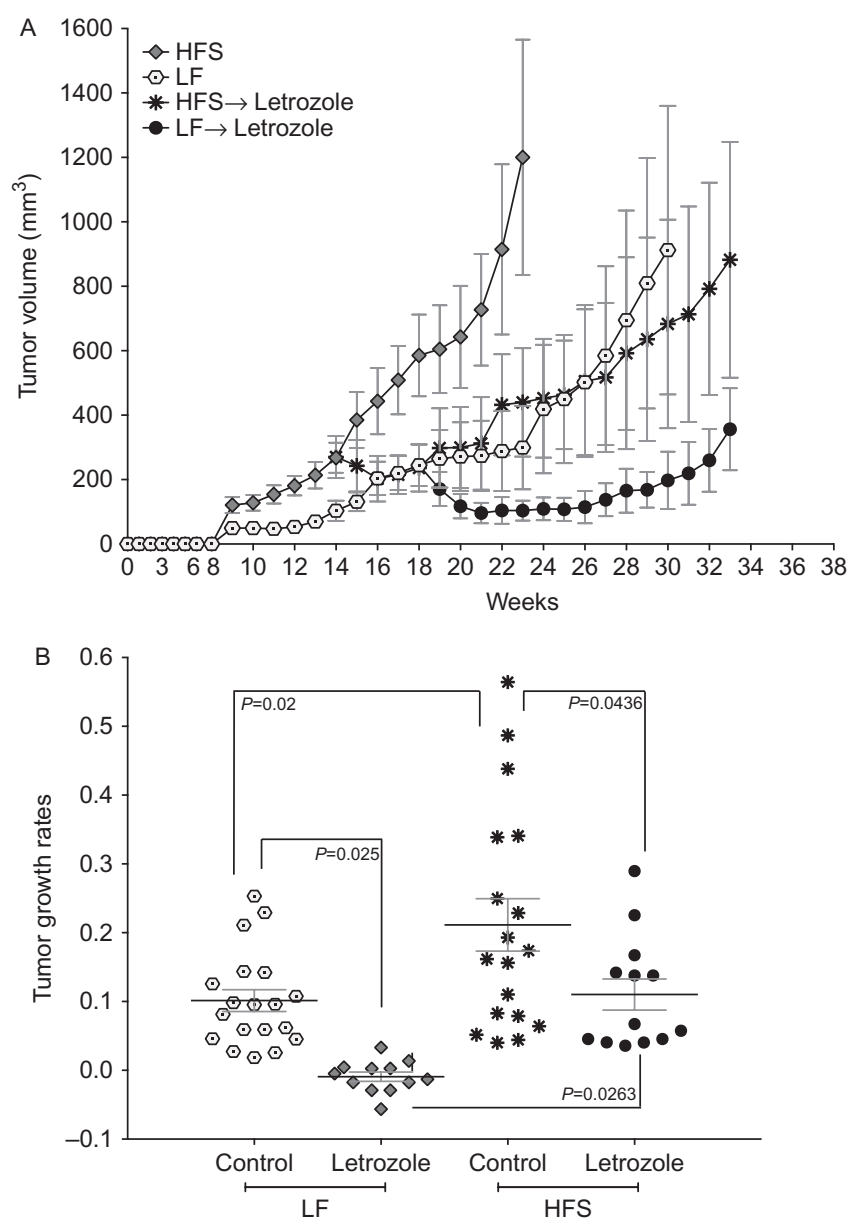

Figure 7

Effect of HFSD on the growth of MCF-7Ca xenografts. Mice were fed HFS or LF diets for 6 weeks and then MCF-7Ca cells $\left(2.5 \times 10^{6}\right.$ cells in Matrigel/site) were inoculated. The mice were then supplemented with androstenedione $(100 \mu \mathrm{g} / \mathrm{day})$ to support tumor growth. The measurement of the tumors was started 3 weeks after tumor cell inoculation. When the tumors reached $\sim 250 \mathrm{~mm}^{3}$, the mice were grouped to receive letrozole $(10 \mu \mathrm{g} / \mathrm{day})$.

(A) Tumors were measured weekly and volumes were calculated. (B) Growth rates of tumors were calculated using a linear regression model of the log transformed tumor volumes. Tumors of the obese mice have a significantly higher growth rate than the tumors of the lean mice $(P=0.02)$. Although letrozole treatment significantly reduced the growth rate of tumors in both obese $(P=0.0436)$ and lean $(P=0.025)$ mice, letrozoletreated tumors of obese mice have a significantly higher growth rate than the letrozole-treated tumors of the lean mice $(P=0.0263)$.

these studies, AIs were significantly better than tamoxifen in controlling tumor growth in our xenograft model. However, anastrozole was found to be less effective than tamoxifen in overweight and obese patients (Sestak et al. 2010). On the other hand, letrozole was found to be as equally effective as tamoxifen in the BIG 1-98 trial (Ewertz et al. 2012). However, both studies confirmed that obesity increased hazard ratios for disease-free survival and overall survival. The discrepancy in these studies could be due to inadequate inhibition of aromatase by anastrozole compared to letrozole, which further emphasizes that one fixed dose of an AI may not be sufficient in treating patients with varying BMIs.

Previously published studies to investigate obesity have shown that high fat diets together with OVX can lead to an increase in pro-inflammatory cytokines including prostaglandin $\mathrm{PGE}_{2}$, which can increase the expression of aromatase (Subbaramaiah et al. 2011). In this study, we used immune compromised athymic nude mice and observed increases in both COX-2 (an enzyme involved in $\mathrm{PGE}_{2}$ production) and aromatase. As these mice do not have intact immune systems, all of the markers of inflammation may not be expressed. However, athymic nude mice are not completely devoid of an immune system (Shouval et al. 1983, Zhang et al. 2002), and many of the cytokines that are affected by obesity are expressed in nude mice. Our preliminary data showed that several cytokines and adipokines were expressed at comparable levels in nude mice and nonimmune suppressed C57B/6 mice (data not shown). In addition, DIO has been shown to affect immune modulators in athymic nude mice (Lamas et al. 2015). Based on these findings, we propose that the nude mouse model can be useful for studying the effect of DIO on the growth of human tumors and their response to therapy. Furthermore, the interaction of obese cancer-associated adipocytes with human tumors can be studied using this model.

In the current study, we evaluated the effect of the obesogenic diet on the development of metabolic symptoms of obesity in athymic nude mice. We observed that athymic nude mice gain significant weight on a high fat and sugar diet. Higher fasting glucose and insulin levels, impaired glucose tolerance, and increased adiposity accompanied the weight gain. Next, we examined the effect of obesity on the growth of human breast cancer tumors and their response to AI letrozole. We observed that obese mice exhibited greater tumor growth rates and diminished response to letrozole compared to lean mice. This reduced responsiveness could be attributed to higher aromatase expression in the adipose tissue and an abundance of adipose tissue resulting in inadequate inhibition at the given dose of letrozole. Heterogeneity in response and resistance to AIs is not completely understood and we hypothesize that the presence of obesity (and its underlying molecular phenotype) is one of the responsible factors. The tumors may also develop letrozole resistance faster due to higher serum levels of insulin, which stimulates tumor growth. The results of this study suggest that the breast cancer tumors growing in an

Published by Bioscientifica Ltd. 
obese microenvironment respond to treatments differently than the tumors growing in a lean microenvironment and therefore should be treated differently. However, currently presence of obesity is not taken into account when selecting a treatment regimen.

\section{Supplementary data}

This is linked to the online version of the paper at http://dx.doi.org/10.1530/ ERC-15-0168.

\section{Declaration of interest}

The authors declare that there is no conflict of interest that could be perceived as prejudicing the impartiality of the research reported.

\section{Funding}

Research reported in this publication was supported by the Mid-Atlantic Nutrition Obesity Research Center (NORC) under NIH award number P30DK072488. This work was also supported by a grant to $G$ Sabnis (KG10037) from Susan G Komen for the Cure.

\section{References}

Andrikopoulos S, Blair AR, Deluca N, Fam BC \& Proietto J 2008 Evaluating the glucose tolerance test in mice. American Journal of Physiology. Endocrinology and Metabolism 295 E1323-E1332. (doi:10.1152/ajpendo. 90617.2008)

Anstee QM \& Goldin RD 2006 Mouse models in non-alcoholic fatty liver disease and steatohepatitis research. International Journal of Experimental Pathology 87 1-16. (doi:10.1111/j.0959-9673.2006.00465.x)

Baum M, Budzar AU, Cuzick J, Forbes J, Houghton JH, Klijn JG \& Sahmoud T 2002 Anastrozole alone or in combination with tamoxifen versus tamoxifen alone for adjuvant treatment of postmenopausal women with early breast cancer: first results of the ATAC randomised trial. Lancet 359 2131-2139. (doi:10.1016/S0140-6736(02)09088-8)

Bell M, Wang H, Chen H, McLenithan JC, Gong DW, Yang RZ, Yu D, Fried SK, Quon MJ, Londos C et al. 2008 Consequences of lipid droplet coat protein downregulation in liver cells: abnormal lipid droplet metabolism and induction of insulin resistance. Diabetes $\mathbf{5 7}$ 2037-2045. (doi:10.2337/db07-1383)

Brodie AM, Lu Q, Long BJ, Fulton A, Chen T, Macpherson N, DeJong PC Blankenstein MA, Nortier JW, Slee PH et al. 2001 Aromatase and COX-2 expression in human breast cancers. Journal of Steroid Biochemistry and Molecular Biology 79 41-47. (doi:10.1016/S0960-0760(01)00131-5)

Champ CE, Volek JS, Siglin J, Jin L \& Simone NL 2012 Weight gain, metabolic syndrome, and breast cancer recurrence: are dietary recommendations supported by the data? International Journal of Breast Cancer 2012 506868. (doi:10.1155/2012/506868)

Ewertz M, Gray KP, Regan MM, Ejlertsen B, Price KN, Thurlimann B, Bonnefoi H, Forbes JF, Paridaens RJ, Rabaglio M et al. 2012 Obesity and risk of recurrence or death after adjuvant endocrine therapy with letrozole or tamoxifen in the breast international group 1-98 trial. Journal of Clinical Oncology 30 3967-3975. (doi:10.1200/JCO. 2011.40.8666)

Goss PE 2006 Preventing relapse beyond 5 years: the MA.17 extended adjuvant trial. Seminars in Oncology 33 S8-12. (doi:10.1053/j.seminoncol.2006.03.025)
Goss PE, Ingle JN, Martino S, Robert NJ, Muss HB, Piccart MJ, Castiglione M, $\mathrm{Tu}$ D, Shepherd LE, Pritchard KI et al. 2003 A randomized trial of letrozole in postmenopausal women after five years of tamoxifen therapy for early-stage breast cancer. New England Journal of Medicine 349 1793-1802. (doi:10.1056/NEJMoa032312)

Goss PE, Ingle JN, Martino S, Robert NJ, Muss HB, Piccart MJ, Castiglione M, Tu D, Shepherd LE, Pritchard KI et al. 2005 Randomized trial of letrozole following tamoxifen as extended adjuvant therapy in receptor-positive breast cancer: updated findings from NCIC CTG MA.17. Journal of the National Cancer Institute 97 1262-1271. (doi:10.1093/jnci/dji250)

Johnston SR 2005 Clinical trials of intracellular signal transductions inhibitors for breast cancer - a strategy to overcome endocrine resistance. Endocrine-Related Cancer 12 (Suppl 1) S145-S157. (doi:10.1677/erc.1.00992)

Johnston SR 2006 Clinical efforts to combine endocrine agents with targeted therapies against epidermal growth factor receptor/human epidermal growth factor receptor 2 and mammalian target of rapamycin in breast cancer. Clinical Cancer Research 12 1061s-1068s. (doi:10.1158/1078-0432.CCR-05-2125)

Johnston SR, Leary A, Martin LA, Smith IE \& Dowsett M 2008 Enhancing endocrine response with novel targeted therapies: why have the clinical trials to date failed to deliver on the preclinical promise? Cancer 112 710-717. (doi:10.1002/cncr.23190)

Jones ME, Thorburn AW, Britt KL, Hewitt KN, Wreford NG, Proietto J, $\mathrm{Oz}$ OK, Leury BJ, Robertson KM, Yao S et al. 2000 Aromatase-deficient (ArKO) mice have a phenotype of increased adiposity. PNAS 97 12735-12740. (doi:10.1073/pnas.97.23.12735)

Karuppu D, Kalus A, Simpson ER \& Clyne C 2002 Aromatase and prostaglandin inter-relationships in breast adipose tissue: significance for breast cancer development. Breast Cancer Research and Treatment 76 103-109. (doi:10.1023/A:1020531329686)

Lamas B, Nachat-Kappes R, Goncalves-Mendes N, Mishellany F, Rossary A, Vasson MP \& Farges MC 2015 Dietary fat without body weight gain increases in vivo MCF-7 human breast cancer cell growth and decreases natural killer cell cytotoxicity. Molecular Carcinogenesis 54 58-71. (doi:10.1002/mc.22074)

Langston WC \& Robinson BL 1935 Castration Atrophy. A chronological study of uterine changes following bilateral ovariectomy in the albino rat. Endocrinology 19 51-62. (doi:10.1210/endo-19-1-51)

Long BJ, Tilghman SL, Yue W, Thiantanawat A, Grigoryev DN \& Brodie AM 1998 The steroidal antiestrogen ICI 182,780 is an inhibitor of cellular aromatase activity. Journal of Steroid Biochemistry and Molecular Biology 67 293-304. (doi:10.1016/S0960-0760(98)00122-8)

Maffei L, Murata Y, Rochira V, Tubert G, Aranda C, Vazquez M, Clyne CD, Davis S, Simpson ER \& Carani C 2004 Dysmetabolic syndrome in a man with a novel mutation of the aromatase gene: effects of testosterone, alendronate, and estradiol treatment. Journal of Clinical Endocrinology and Metabolism 89 61-70. (doi:10.1210/jc.2003-030313)

Maliqueo M, Sun M, Johansson J, Benrick A, Labrie F, Svensson H, Lonn M, Duleba AJ \& Stener-Victorin E 2013 Continuous administration of a P450 aromatase inhibitor induces polycystic ovary syndrome with a metabolic and endocrine phenotype in female rats at adult age. Endocrinology 154 434-445. (doi:10.1210/en.2012-1693)

Morris PG, Hudis CA, Giri D, Morrow M, Falcone DJ, Zhou XK, Du B, Brogi E, Crawford CB, Kopelovich L et al. 2011 Inflammation and increased aromatase expression occur in the breast tissue of obese women with breast cancer. Cancer Prevention Research 4 1021-1029. (doi:10.1158/ 1940-6207.CAPR-11-0110)

Nkhata KJ, Ray A, Dogan S, Grande JP \& Cleary MP 2009 Mammary tumor development from T47-D human breast cancer cells in obese ovariectomized mice with and without estradiol supplements. Breast Cancer Research and Treatment 114 71-83. (doi:10.1007/s10549008-9991-7)

Owens JW \& Ashby J 2002 Critical review and evaluation of the uterotrophic bioassay for the identification of possible estrogen agonists and antagonists: in support of the validation of the OECD 
uterotrophic protocols for the laboratory rodent. Organisation for Economic Co-operation and Development. Critical Reviews in Toxicology 32 445-520. (doi:10.1080/20024091064291)

Panchal SK \& Brown L 2011 Rodent models for metabolic syndrome research. Journal of Biomedicine \& Biotechnology 2011351982. (doi:10.1155/2011/351982)

Panchal SK, Poudyal H, Iyer A, Nazer R, Alam A, Diwan V, Kauter K, Sernia C, Campbell F, Ward L et al. 2011 High-carbohydrate high-fat diet-induced metabolic syndrome and cardiovascular remodeling in rats. Journal of Cardiovascular Pharmacology 57 51-64. (doi:10.1097/FJC. Ob013e3181feb90a)

Redig AJ \& Munshi HG 2010 Care of the cancer survivor: metabolic syndrome after hormone-modifying therapy. American Journal of Medicine 123 87e81-87e86. (doi:10.1016/j.amjmed.2009.06.022)

Sabnis GJ, Jelovac D, Long B \& Brodie A 2005 The role of growth factor receptor pathways in human breast cancer cells adapted to long-term estrogen deprivation. Cancer Research 65 3903-3910. (doi:10.1158/ 0008-5472.CAN-04-4092)

Sabnis GJ, Macedo LF, Goloubeva O, Schayowitz A \& Brodie AM 2008 Stopping treatment can reverse acquired resistance to letrozole. Cancer Research 68 4518-4524. (doi:10.1158/0008-5472.CAN-07-5999)

Sabnis G, Schayowitz A, Goloubeva O, Macedo L \& Brodie A 2009 Trastuzumab reverses letrozole resistance and amplifies the sensitivity of breast cancer cells to estrogen. Cancer Research 69 1416-1428. (doi:10.1158/0008-5472.CAN-08-0857)

Sabnis G, Goloubeva O, Gilani R, Macedo L \& Brodie A 2010 Sensitivity to the aromatase inhibitor letrozole is prolonged after a "break" in treatment. Molecular Cancer Therapeutics 9 46-56. (doi:10.1158/15357163.MCT-09-0696)

Sabnis GJ, Goloubeva OG, Kazi AA, Shah P \& Brodie AH 2013a HDAC inhibitor entinostat restores responsiveness of letrozole resistant MCF-7Ca xenografts to AIs through modulation of Her-2. Molecular Cancer Therapeutics 12 2804-2816. (doi:10.1158/1535-7163.MCT-13-0345)

Sabnis GJ, Kazi A, Golubeva O, Shah P \& Brodie A 2013b Effect of selumetinib on the growth of anastrozole-resistant tumors. Breast Cancer Research and Treatment 138 699-708. (doi:10.1007/s10549-0132474-5)

Sestak I, Distler W, Forbes JF, Dowsett M, Howell A \& Cuzick J 2010 Effect of body mass index on recurrences in tamoxifen and anastrozole treated women: an exploratory analysis from the ATAC trial. Journal of Clinical Oncology 28 3411-3415. (doi:10.1200/JCO.2009.27.2021)
Shouval D, Rager-Zisman B, Quan P, Shafritz DA, Bloom BR \& Reid LM 1983 Role in nude mice of interferon and natural killer cells in inhibiting the tumorigenicity of human hepatocellular carcinoma cells infected with hepatitis B virus. Journal of Clinical Investigation 72 707-717. (doi:10.1172/JCI111020)

Simpson ER, Misso M, Hewitt KN, Hill RA, Boon WC, Jones ME, Kovacic A, Zhou J \& Clyne CD 2005 Estrogen - the good, the bad, and the unexpected. Endocrine Reviews 26 322-330. (doi:10.1210/er.2004-0020)

Subbaramaiah K, Howe LR, Bhardwaj P, Du B, Gravaghi C, Yantiss RK, Zhou XK, Blaho VA, Hla T, Yang P et al. 2011 Obesity is associated with inflammation and elevated aromatase expression in the mouse mammary gland. Cancer Prevention Research 4 329-346. (doi:10.1158/ 1940-6207.CAPR-10-0381)

Subbaramaiah K, Howe LR, Zhou XK, Yang P, Hudis CA, Kopelovich L \& Dannenberg AJ 2012 Pioglitazone, a PPAR $\gamma$ agonist, suppresses CYP19 transcription: evidence for involvement of 15-hydroxyprostaglandin dehydrogenase and BRCA1. Cancer Prevention Research 5 1183-1194. (doi:10.1158/1940-6207.CAPR-12-0201)

Thurlimann B, Keshaviah A, Coates AS, Mouridsen H, Mauriac L, Forbes JF, Paridaens R, Castiglione-Gertsch M, Gelber RD, Rabaglio M et al. 2005 A comparison of letrozole and tamoxifen in postmenopausal women with early breast cancer. New England Journal of Medicine 353 2747-2757. (doi:10.1056/NEJMoa052258)

Yue W \& Brodie A 1993 MCF-7 human breast carcinomas in nude mice as a model for evaluating aromatase inhibitors. Journal of Steroid Biochemistry and Molecular Biology 44 671-673. (doi:10.1016/09600760(93)90278-5)

Yue W, Zhou D, Chen S \& Brodie A 1994 A new nude mouse model for postmenopausal breast cancer using MCF-7 cells transfected with the human aromatase gene. Cancer Research 54 5092-5095.

Zhang F, Lu W \& Dong Z 2002 Tumor-infiltrating macrophages are involved in suppressing growth and metastasis of human prostate cancer cells by INF- $\beta$ gene therapy in nude mice. Clinical Cancer Research 8 2942-2951.

Zhao Y, Agarwal VR, Mendelson CR \& Simpson ER 1996 Estrogen biosynthesis proximal to a breast tumor is stimulated by PGE2 via cyclic AMP, leading to activation of promoter II of the CYP19 (aromatase) gene. Endocrinology 137 5739-5742.

Zhou DJ, Pompon D \& Chen SA 1990 Stable expression of human aromatase complementary DNA in mammalian cells: a useful system for aromatase inhibitor screening. Cancer Research 50 6949-6954.

Received in final form 10 June 2015

Accepted 18 June 2015

Made available online as an Accepted Preprint

25 June 2015
(C) 2015 Society for Endocrinology Printed in Great Britain 